\title{
ENHANCED REMOVAL OF CRYSTAL VIOLET DYE USING ZINC OXIDE NANORODS AND AIR OXIDATION UNDER SUNLIGHT RADIATION
}

\author{
Preeja. P. Thattil and A. Leema Rose* \\ Department of Chemistry, Holy Cross College (Autonomous), Affiliated to Bharathidasan \\ University, Tiruchirappalli-620 002, Tamil Nadu, India. \\ E-mail: leemarose25@gmail.com
}

\begin{abstract}
A simple chemical precipitation method is employed for the synthesis of $\mathrm{ZnO}$ nanorods using zinc acetate precursor in basic medium. The synthesized zinc oxide nanoparticles are characterized using x-ray diffraction analysis, transmission electron microscopy, diffuse reflectance spectroscopy, photoluminescence and bet surface area analysis. These zinc oxide nanorods are used for the photocatalytic decolorization of crystal violet dye and the rate enhancement is achieved by air purging under sunlight radiation. Effective dye removal is attained by optimizing the parameters such as the effect of $\mathrm{pH}$, catalyst dosage and initial dye concentration and the nature of the interaction of hydroxyl and superoxide anion radicals with the crystal violet dye is discussed in this paper.
\end{abstract}

Keywords: ZnO Nanorods, Crystal Violet, Air Oxidation, Solar Radiation.

(C) RASĀYAN. All rights reserved

\section{INTRODUCTION}

A very large amount of dye effluents is being released by various industrial processes such as paper and pulp manufacturing, plastics, dyeing of cloth, leather treatment and printing which have been considerably increased over the last few decades. ${ }^{1,2}$ Synthetic organic dyes from the textile industries are mainly non-biodegradable, creating major environmental pollution and health hazards. Crystal violet is one such cationic, triaryl methane dye which is widely used in the preparation of navy blue and black inks for printing purposes. It is also used as a coloring agent for various products such as fertilizers, types of antifreeze, detergents, and leather. The dye is also used as a histological $\operatorname{stain}^{3-5}$ despite its extensive applications, crystal violet is reported to be persistent in the environment for a long duration and hence it poses a toxic effect to the aquatic and human life and therefore it is regarded to be a biohazard substance. Since this dye molecule is considered to be a toxic agent ${ }^{6,7}$ it has to be eliminated, by converting it into eco-friendly products using a large variety of semiconductor nanoparticles is considered to be a demanding area of research. Many scientific reports suggested the use of semiconductor photocatalyst for the efficient conversion of organic pollutants into relatively harmless products such as minerals, $\mathrm{CO}_{2}$ and water $^{8,9} . \mathrm{ZnO}$ is an n-type semiconductor photocatalyst with a large number of active sites. It has a wide bandgap of $3.2 \mathrm{Ev}{ }^{10}$ Surface and core defects, such as oxygen vacancies, zinc and oxygen interstitials provide active sites for preventing the electron-hole recombination. This, in turn, enhances the generation of superoxide and hydroxyl radicals, which is found to be responsible for the photocatalytic dye degradation process. ${ }^{11,12}$ Thus, $\mathrm{ZnO}$ is extensively studied as a photocatalyst in water treatment application due to its low cost, favorable optical, electronic and catalytic properties. ${ }^{13,14}$ Recently, Nirmalya Tripathy et al., reported the photocatalytic degradation of crystal violet dye under UV irradiation using $\mathrm{ZnO}$ nanonails. ${ }^{15}$ In 2010 , Swaminathan et al. confirmed the photocatalytic degradation of Acid Black 1 dye by cyclic voltammetric measurements and Chemical Oxygen Demand analysis. ${ }^{16}$ Srivastava et al., reported the synthesis of zinc oxide semiconductor nanoparticles by electrochemical method for the degradation of nitrobenzene and azo dye. ${ }^{17}$ In this paper, we report the photocatalytic degradation of crystal violet dye using zinc oxide nanorods enhanced by air oxidation under sunlight. The

Rasayan J. Chem., 13(2), 1166-1173(2020)

http://dx.doi.org/10.31788/RJC.2020.1325558 
RASĀYAN J. Chem.

Vol. 13 | No. 2 |1166 - 1173| April - June | 2020

results obtained from the research work showed that about $96 \%$ of the crystal violet dye got degraded within 50 minutes by using the only $25 \mathrm{mg}$ of zinc oxide nanocatalyst which clearly showed that the synthesized zinc oxide nanorods are promising materials for the removal of other triaryl methane class of compounds.

\section{EXPERIMENTAL}

The Zinc acetate Dihydrate salt (M.W. 219.50, purity 98.5\%) was purchased from Sisco Research Laboratories Pvt.Ltd., sodium hydroxide from Merck and ethanol (99.9\%) was purchased from Changshu Hongsheng Fine Chemical Co. Ltd. The capacity of the air pump used for the experiments is $3 \mathrm{~W}$ and air supplied is $2.5 \mathrm{~L} / \mathrm{min}$. Crystal violet dye (molecular formula C25H30ClN3, MW 407.99 and $\lambda \max =590$ $\mathrm{nm}$ ) was obtained from S. D.Fine Chemicals. The chemical structure of the dye is shown in Fig.-1.

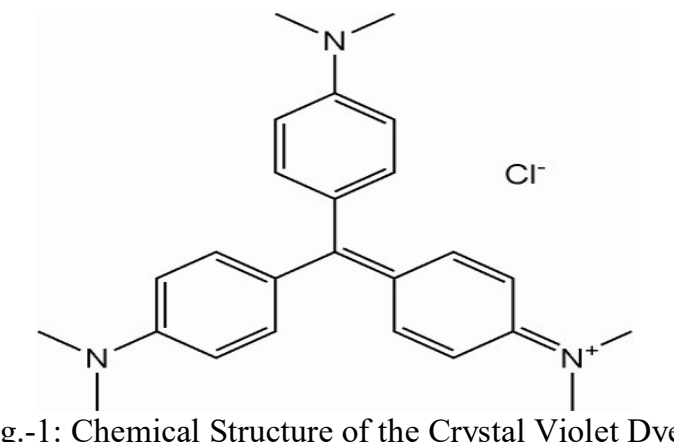

The morphological characterizations of the synthesized zinc oxide nanoparticles were investigated by scanning electron microscopy (JEOL JSM-7600F FEG-SEM) equipped with energy dispersive spectroscopy (EDS-Bruker), and transmission electron microscopy (TEM CM 200). The crystallinity and crystal phase of the as-synthesized $\mathrm{ZnO}$ nanoparticles were analyzed by X-ray diffraction (XRD, Rigaku) patterns with $\mathrm{Cu}-\mathrm{k} \alpha$ Radiation $(\lambda=1.54178 \AA)$ at a scan rate of $40 \mathrm{kV}$. To study the recombination of electron-holes in the photocatalyst, the PL emission spectrum of the sample is measured with Shimadzu/RF6000 and the bandgap of the semiconductor is determined by the diffuse reflectance spectroscopy (Shimadzu/ UV 2600). The surface area and pore volume are determined by the nitrogen adsorption/desorption analyzer.

\section{General Procedure}

\section{Synthesis of Zinc Oxide Nanoparticles}

Zinc acetate dihydrate is used as a precursor to prepare the zinc oxide nanoparticles. About $0.5 \mathrm{~g}$ of zinc acetate dihydrate is dissolved in a minimum quantity of double-distilled water. $2 \mathrm{~mL}$ of ethanol and sodium hydroxide is used as a strong base to precipitate the salt solution. A thick white precipitate is obtained and the mixture is stirred continuously for 30 minutes and then dried in the hot air oven at $100^{\circ} \mathrm{C}$ for 3 hours and then it is calcined at $450^{\circ} \mathrm{C}$.

\section{Photocatalytic Degradation Experiments}

The varying stock solutions of crystal violet dye $(10 \mathrm{mg}$ to $50 \mathrm{mg} / \mathrm{L})$ is prepared, from which $50 \mathrm{~mL}$ was withdrawn for each experiment. All the photocatalytic experiments were carried out on sunny days between 11 am to $2 \mathrm{pm}$. Before, exposing the dye solution to sunlight irradiation the initial absorption peak was recorded. The reaction was carried out in the open air and the solution was continuously mixed by pumping to provide aeration. The experiment was continued for 3 hours, at appropriate intervals $2 \mathrm{~mL}$ of the dye solution is withdrawn and centrifuged to separate the catalyst. The effect of $\mathrm{pH}$ was studied by adjusting the solution using $0.1 \mathrm{~N} \mathrm{NaOH}$ and $0.1 \mathrm{~N} \mathrm{HCl}$. The blank experiments were performed in the dark at room temperature following the above procedure. The percentage decolorization was calculated using the formula:

$$
\frac{C 0-C}{C 0} \times 100
$$


Where $\mathrm{C}_{0}$ is the initial concentration of the dye solution and $\mathrm{C}$ is the concentration of the dye solution at time t.

\section{Catalyst Characterization}

\section{RESULTS AND DISCUSSION}

The morphology of the synthesized zinc oxide nanocatalyst is examined by FESEM and TEM analysis.
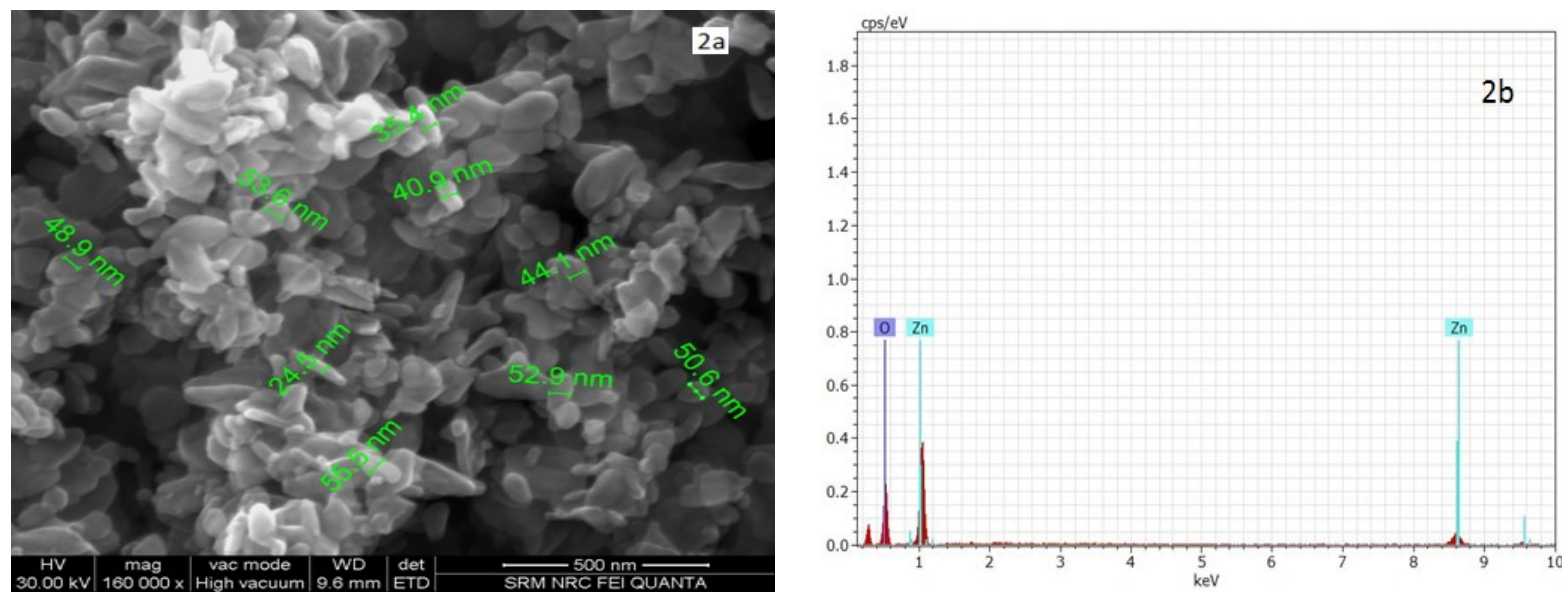

Fig.-2: $\mathrm{a}$ and $\mathrm{b}$ shows the FE-SEM Images and the EDAX Spectrum of the Synthesized Zinc Oxide Nanoparticles
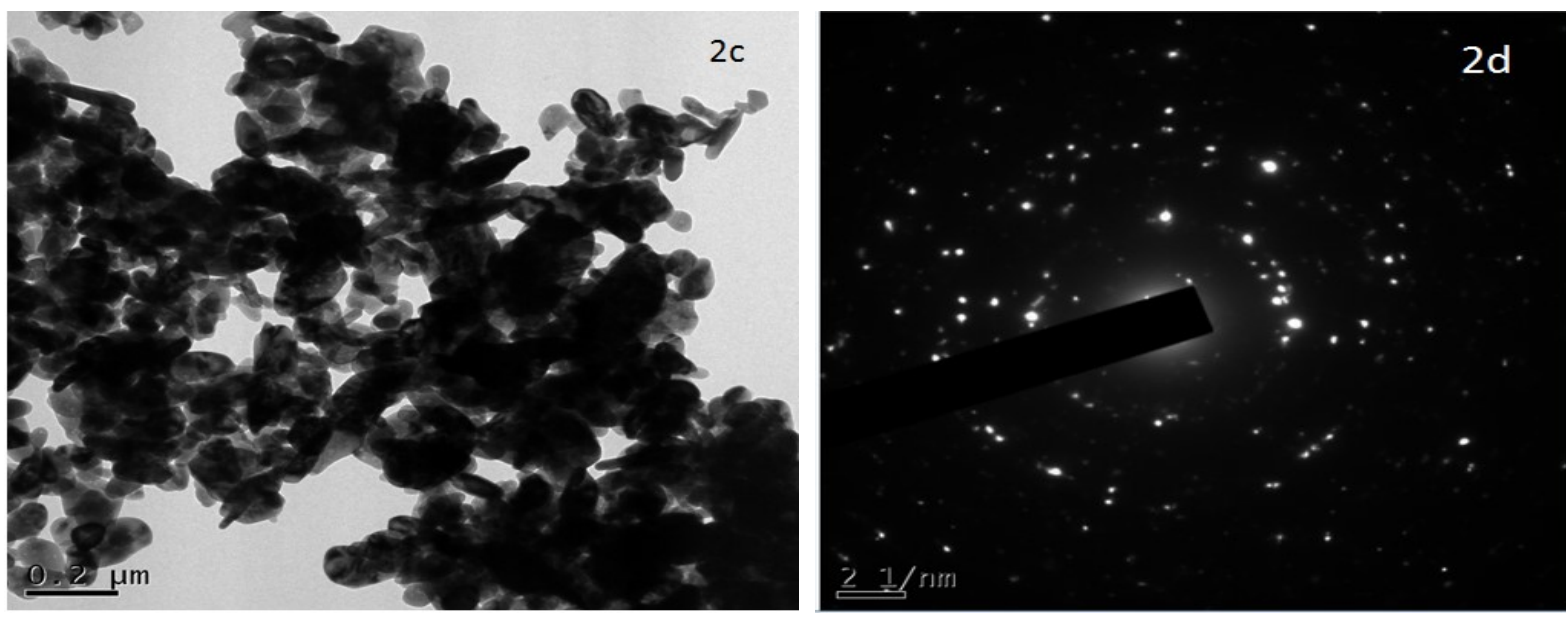

Fig.-2c and $2 \mathrm{~d}$ show the TEM Images of the Synthesized Zinc Oxide Nanoparticles.

From Figs.-2a and 2c it is found that the synthesized zinc oxide particles posses a moderate rod-like structure with the particle size ranging from $24.5 \mathrm{~nm}$ to $55.5 \mathrm{~nm}$. Additionally, the dark-spotted circles in the SAED pattern indicate the crystalline nature of the zinc oxide nanorods. This result is in agreement with that found to zinc oxide nanoparticles prepared from similar precursors ${ }^{18,19}$. The typical EDAX spectrum of the zinc oxide particles in Fig.-2b shows the presence of zinc and oxygen elements in major composition which confirms the successful formation of zinc oxide nanoparticles without any impurities. Further, the crystallinity, band gap value, surface area, optical property, and structural disorders and the defects of the as-synthesized $\mathrm{ZnO}$ nanorods were examined by XRD, UV-DRS, nitrogen adsorptiondesorption analyzer and room-temperature PL spectrum, respectively.

XRD spectrum of the synthesized zinc oxide nanoparticles shows that all the diffraction peaks were indexed to the hexagonal wurtzite phase of zinc oxide. The diffraction peaks at $2 \theta=31.8,34.5,36.4$, 47.6, 56.8, and 63.0 shown in Fig.-3a corresponds to the crystal planes (100), (002), (101), (102), (110), and (103), respectively, which is following the JCPDS file no. $36-1451 .{ }^{20}$ From the obtained XRD results, 
RASĀYAN J. Chem.

Vol. 13 | No. 2 |1166 - 1173| April - June | 2020

it is found that (101) peak is the most intense one which is also the preferred growth plane of zinc oxide nanoparticles. Bandgap energy $(\mathrm{Eg})$ of the zinc oxide nanocatalyst is obtained using the following relation:

$$
\operatorname{Eg}=\frac{1240}{\lambda}
$$

Where, Eg is the bandgap energy in electron volts $(\mathrm{eV})$ and $\lambda$ is the wavelength $(\mathrm{nm})$ corresponding to maximum absorption. The Eg of nanocatalyst synthesized using chemical precipitation method was found to be $3.12 \mathrm{eV}$ respectively (as shown in Fig. $-3 \mathrm{~b}$ ), which matches well with literature. ${ }^{21}$ Room temperature Photoluminescence spectrum of $\mathrm{ZnO}$ generally shows three major peaks: the first peak is a UV emission peak around $380 \mathrm{~nm}$, the second peak is a green emission peak around $520 \mathrm{~nm}$ and the third is a red or orange emission peak around $600 \mathrm{~nm} .{ }^{22}$ PL spectrum of the synthesized zinc oxide nanoparticles was recorded with $254 \mathrm{~nm}$ excitation (Fig.-3c). PL emission curve of as formed $\mathrm{ZnO}$ nanorods showed a peak at $396 \mathrm{~nm}$ which may be due to the electron-hole pair recombination or band to band recombination ${ }^{23,24}$ and the broad green emission peak at $523 \mathrm{~nm}$ correspond to the presence of singly ionized oxygen vacancies. ${ }^{25}$ The surface area is one of the most important factors that influence the catalytic activity of the semiconductor nanoparticles. The nitrogen adsorption-desorption isotherms of the as-synthesized zinc oxide nanoparticles are shown in Fig.-3d. From the BET surface area measurements, it is found that the specific surface area of the zinc oxide nanocatalyst is $19.593 \mathrm{~m}^{2} / \mathrm{g}$ and its pore volume is $0.099 \mathrm{cc} / \mathrm{g}$.
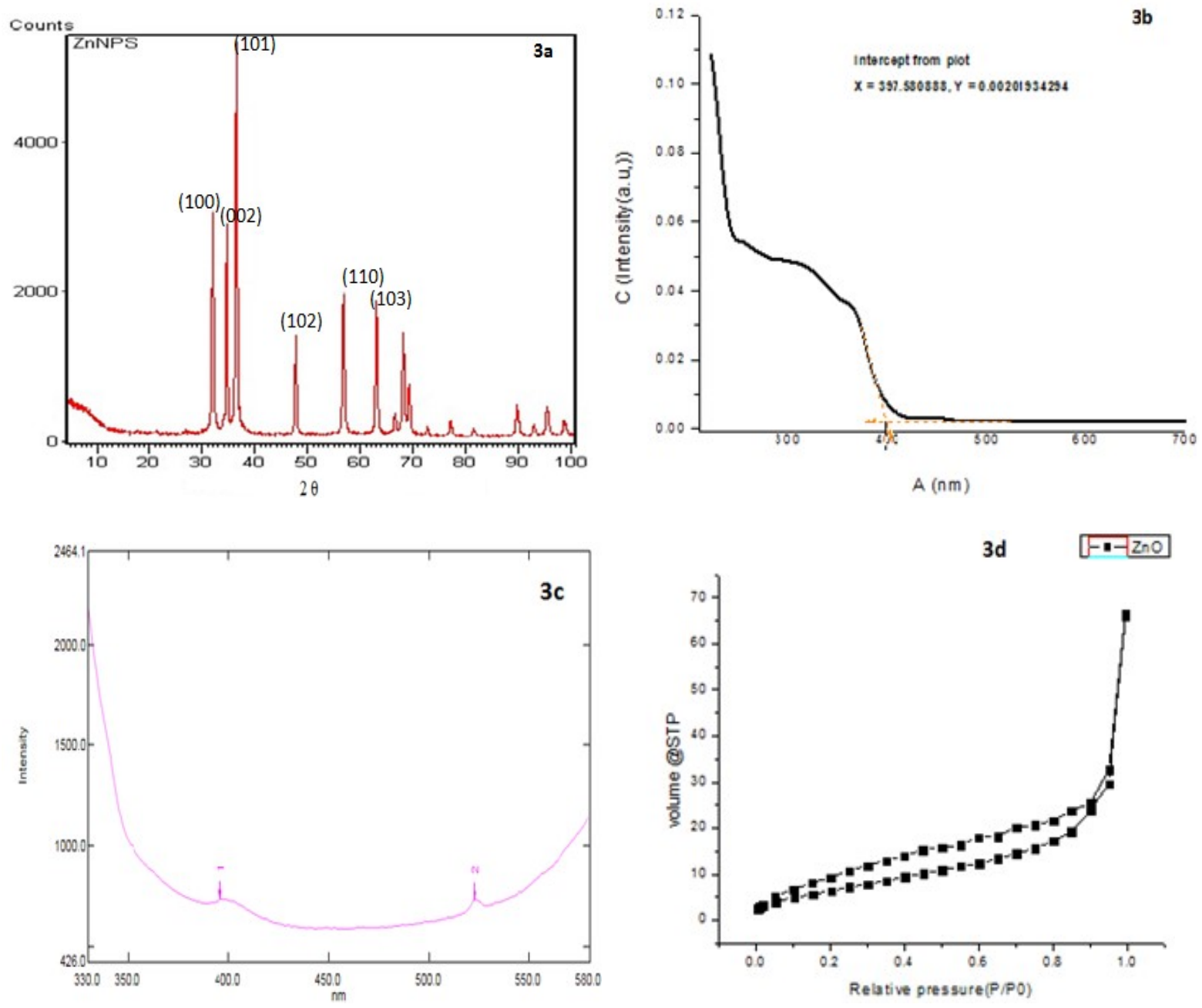

Fig.-3: 3a shows the XRD Pattern of the Synthesized ZnO Nanoparticles, 3b shows the UV-DRS Plot for the Synthesized ZnO Nanoparticles, 3c shows the PL Spectrum of the Synthesized ZnO Nanoparticles and 3d shows the $\mathrm{N}_{2}$ Adsorption-Desorption Isotherm Pattern of ZnO Nanoparticles 
RASĀYAN J. Chem.

Vol. 13 | No. 2 |1166 - 1173| April - June | 2020

\section{Photocatalytic Degradation of Crystal Violet Dye \\ Effect of pH}

The effect of $\mathrm{pH}$ in the range of 3-12 and experimental conditions $(25 \mathrm{mg}$ of $\mathrm{ZnO}$ catalyst, $10 \mathrm{mg} / \mathrm{L}$ dye concentration) on the overall rate of decolorization is studied. The maximum decolorization efficiency was obtained in alkaline $\mathrm{pH}=10$ shown in Fig.-4. This may be because, in acidic $\mathrm{pH}$ values, the photodecomposition of zinc oxide nanoparticles may take place. ${ }^{26}$ On the other hand, there is an increase in several hydroxyl ions, at higher $\mathrm{pH}$ values and it consequently leads to an increase in the photodecolorization process. But when the $\mathrm{pH}$ value is so high there is an abundant number of hydroxyl ions around catalyst which compete with dye molecules in adsorption on the surface of photocatalyst; this causes a decrease in photodecolorization efficiency. ${ }^{27}$

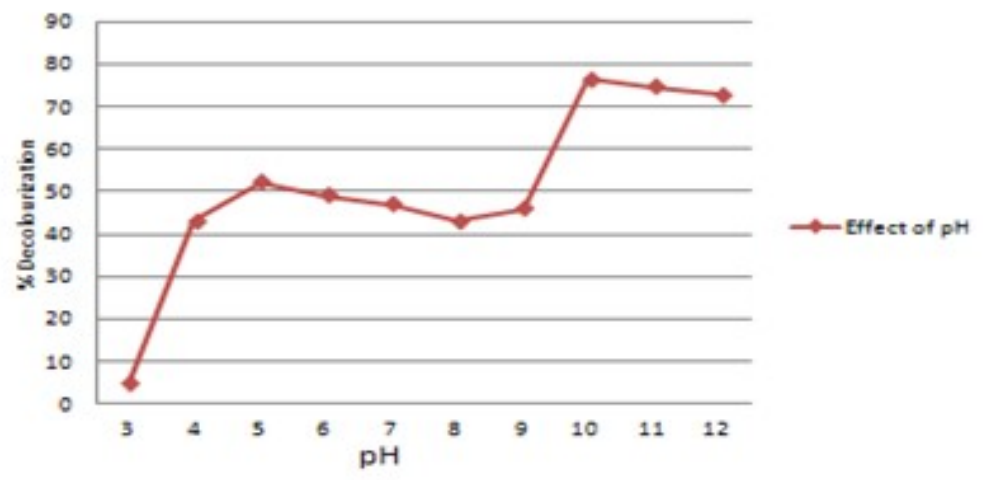

Fig.-4: $0.01 \mathrm{~g} / \mathrm{L}$ Crystal Violet Dye Solution, $25 \mathrm{mg}$ of $\mathrm{ZnO}$ Catalyst, $\mathrm{pH}$ varied from 3 to 12, Airflow Rate = $2.5 \mathrm{~L} / \mathrm{min}$ under Sunlight.

\section{Effect of Catalyst Dosage}

The optimum amount of zinc oxide catalyst for the effective decolorization of crystal violet dye is found out by varying the catalyst concentration from $5 \mathrm{mg}$ to $55 \mathrm{mg}$ for $10 \mathrm{mg} / \mathrm{L}$ of the dye solution shown in Fig.-5. Initially, by increasing the catalyst concentration till $25 \mathrm{mg}$ there is an increase in dye degradation beyond which a decrease in the decolorization rate is observed. This is due to fact that active sites required for the photocatalytic dye decolorization increases by increasing the catalyst concentration and beyond the addition of $25 \mathrm{mg}$ of catalyst to the dye solution there is an increase in the turbidity of the suspension and decrease in sunlight penetration occurs as a result of which a decrease in the photodecolorization process is observed. ${ }^{28}$

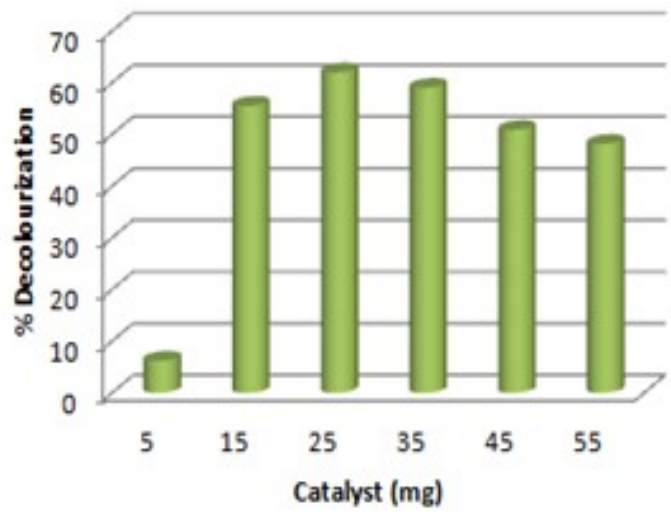

E Effect of Catalyst concentration

Fig.-5: $0.01 \mathrm{~g} / \mathrm{L}$ Crystal Violet Dye Solution, ZnO Catalyst Dosage Varied from 5mg to 55mg, pH = 10, Air Flow Rate $=2.5 \mathrm{~L} / \mathrm{min}$ under Sunlight. 
RASĀYAN J. Chem.

Vol. 13 | No. 2 |1166 - 1173| April - June | 2020

\section{Effect of Initial Dye Concentration}

Only a negligible percentage of the dye gets decolorized in the absence of the catalyst which shows that it is resistant to self photolysis. About $96 \%$ of crystal violet dye got degraded within 50 minutes in the presence of $\mathrm{ZnO}$ catalyst, air oxidation under solar light at $\mathrm{pH}=10$. From these findings, it is clear that solar light, air oxidation and a semiconductor photocatalyst are needed for the effective degradation of crystal violet dye. The effect of varying initial dye concentrations on the degradation of crystal violet dye with $\mathrm{ZnO}$ has been investigated by selecting a concentration range of $10 \mathrm{mg} / \mathrm{L}$ to $50 \mathrm{mg} / \mathrm{L}$ under the experimental conditions of catalyst concentration $25 \mathrm{mg}, \mathrm{pH}$ range 10 and continuous air oxidation which is shown in Fig.-6. The experimental results show that an increase in dye degradation up to $30 \mathrm{mg} / \mathrm{L}$ of dye solution is observed beyond which there is a decrease in the rate of the degradation process. The formation of hydroxyl radicals and its ability to react with dye molecules decides the rate of the dye degradation process. At higher dye concentrations there is a decrease in the probability of the dye molecules to react with $\mathrm{OH}$ radicals and hence a decrease in the dye degradation rate is observed. ${ }^{29}$

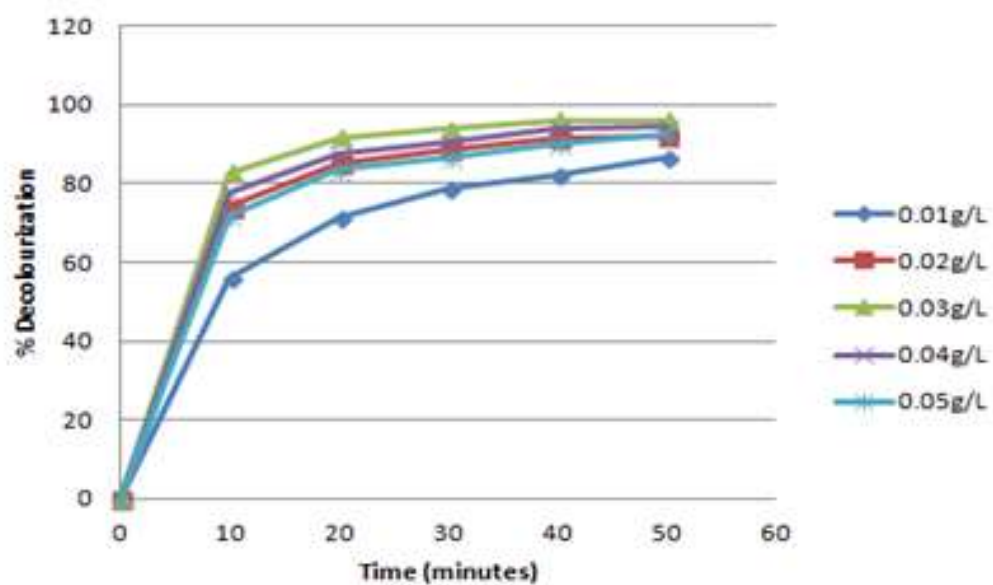

Fig.-6:25mg of ZnO Catalyst, $\mathrm{pH}=10$, Initial Crystal Violet Dye Concentration Varied from 0.01g/L to 0.05g/L, Air Flow Rate $=2.5 \mathrm{~L} / \mathrm{min}$ under Sunlight.

\section{Degradation Mechanism}

Under solar irradiation, the electron gets excited from the valence band of $\mathrm{ZnO}$ to the conduction band which leads to the generation of an electron and hole ${ }^{30,31}$. Then the electron and holes generated take part in the photocatalytic degradation process by producing highly reactive radical species like hydroxyl and superoxide radicals which react with the dye molecules to give non-hazardous degradation products.

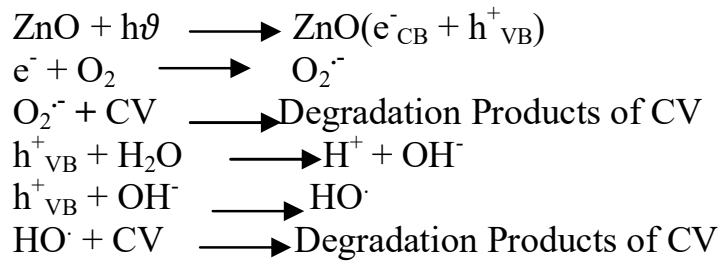

The major products of degradation of crystal violet dye in aqueous solution by advanced oxidation processes were reported by other researchers. According to Huan he et al., ${ }^{32}$ the photocatalytic degradation of $\mathrm{CV}$ took place by three major processes such as $\mathrm{N}$-de-methylation, destruction of conjugated structure and opening-benzene ring and the major products obtained in the destruction of $\mathrm{CV}$ dye was reported to be a series of N-de-methylated products and in the secondary stage organic acids, such as oxalic acid, terephthalic acid, phthalic acid, benzoic acid and 3-hydroxybenzoic acid and so on, were the low molecular intermediates which resulted from the cleavage of the triphenylmethane ring in CV structure. Similar findings were reported by Hongzhe Chen et al., ${ }^{33}$ the intermediates and products formed in the process of degradation of CV dye were mono-, di-, tri-N-de-methylated intermediates 
corresponding to the $\mathrm{m} / \mathrm{z}$ peaks $372,358,344$ and 330 detected by the LC-MS analysis and he also reported the presence of another peak with $\mathrm{m} / \mathrm{z}$ of 371 which might be due to the isomerization of $\mathrm{CV}$ and this intermediate undergoes a faster degradation than with that of $\mathrm{CV}$, making it hard to be detected and the intermediates with smaller molecular weight were glycol, 2-hydroxypropanoic acid and pyrocatechol.

\section{CONCLUSION}

$\mathrm{ZnO}$ nanorods were successfully synthesized by a simple chemical precipitation method. Enhanced degradation of crystal violet dye is possible by effective air purging under solar irradiation within a very short period 50 minutes. Thus this simplest, low-cost and effective technique can be employed for the degradation of other triphenylmethane dyes let out from the textile as well as other dyeing industries.

\section{ACKNOWLEDGMENT}

The authors sincerely thank Dr. S. Thennarasu, Sr. Principal Scientist, Department of Organic and BioOrganic Chemistry, Central Leather Research Institute, Chennai, for his valuable suggestions given for the successful completion of the work. We also thank the PG and Research Department of Chemistry, Holy cross-college, Trichy for providing the necessary laboratory facilities.

\section{REFERENCES}

1. Mehtap Ejder-Korucu, Ahmet Gurses, Cetin Dogar, Sanjay K. Sharma and Metin Acikyildiz, 2015, Removal of Organic Dyes from Industrial Effluents: An Overview of Physical and Biotechnological Applications, Scrivener Publishing LLC, Beverly, pp.1-34.

2. H. Ali, Water Air Soil Pollution, 213, 251(2010), DOI:10.1007/s11270-010-0382-4

3. H.C. Thompson Junior, L.G. Rushing, T. Gehring, and R. Lochmann, Journal of Chromatography B: Biomedical Science Applications, 723, 287(1999), DOI:10.1016/s0378-4347(98)00536-2

4. M. Saquib and M. Muneer, Dyes Pigments, 56, 37(2003), DOI:10.1016/S0143-7208(02)00101-8

5. C. Sahoo, A.K. Gupta, and A. Pal, Dyes Pigments, 66, 189(2005), DOI:10.1016/j.dyepig.2004.09.003

6. L.G. Rushing and M.C. Bowman, Journal of Chromatographic Science, 18, 224(1980), DOI: $10.1093 / \mathrm{chromsci} / 18.5 .224$

7. K.A. Adegoke and O.S. Bello, Water Resources and Industry, 12, 8(2015), DOI: $10.1016 /$ j.wri.2015.09.002

8. Loganathan, A. Sivakumar, B. Murugesan and P. Sivakumar, Rasayan Journal of Chemistry, 12(4), 1710(2019), DOI: 10.31788/RJC.2019.1245351

9. H. Sutanto, I. Marhaendrajaya , G. W. Jaya, E. Hidayanto , M. Mukholit, S. Wibowo and Y. Wahyono, Rasayan Journal of Chemistry, 12(1), 138(2019), DOI:10.31788/RJC.2019.1215034

10. R. Dnyaneshwar Shinde, S. Popat Tambade, G. Manohar Chaskar, and M. Kisan Gadave, Drinking Water Engineering Science, 10, 109(2017), DOI:10.5194/dwes-10-109-2017

11. S. Girish Kumar and K.S.R. Koteswara Rao, RSC Advances., 5, 3306(2015), DOI:10.1039/C4RA13299H

12. A. Janotti and C.G. Van de Walle, Republican Prog. Physics, 72, 126501(2009), DOI:10.1088/00344885/72/12/126501

13. N. P. Diantariani, I. Kartini, A. Kuncaka, and E. T. Wahyuni, Rasayan Journal of Chemistry, 13(1), 747(2020), DOI:10.31788/RJC.2020.1315597

14. M. Giruba, J. Christina Rhoda, S. Chellammal and K. Ravichandran, Rasayan Journal of Chemistry, 13 (1), 439(2020), DOI: 10.31788/RJC.2020.1315501

15. Nirmalya Tripathy, Rafiq Ahmad, Jeong Eun Song, Hyun Park, and Gilson Khang, AIMS Materials Science, 4(1), 267(2017), DOI:10.3934/matersci.2017.1.267

16. B. Krishnakumar and M. Swaminathan, Indian Journal of Chemistry, 49A, 1035(2010)

17. V. Anand and V. C. Srivastava, Journal of Scientific and Industrial Research, 75, 632(2016), DOI: $123456789 / 35575$

18. J. C. Qian, Z. X. Chen and L. J. Zhu, Advanced Materials Research, 800, 276(2013),

19. W. Shen, Z. Li, H. Wang, Y. Liu, Q. Guoa, and Y. Zhang, Journal of Hazardous Materials 152, 172(2008), DOI:10.1016/j.jhazmat.2007.06.082 
RASĀYAN J. Chem.

Vol. 13 | No. 2 |1166 - 1173| April - June | 2020

20. L.Y. Yanga, S. Donga, J.H. Suna, J.L. Fenga, Q.H. Wua, S.P. Sunc, Journal of Hazardous Materials, 179, 438(2010), DOI: 10.1016/j.jhazmat.2010.03.023

21. Abebe Balcha, Om Prakash Yadav and Tania Dey, Environmental Science Pollution Research, (2016), DOI: $10.1007 / \mathrm{s} 11356-016-7750-6$

22. Haiping He, Yuxia Wang and youming Zou, Journal of Physics, D: Applied Physics, 36, 2972(2003), DOI: $10.1088 / 0022-3727 / 36 / 23 / 017$

23. Vinod Kumar, S. Som, Vijay Kumar, Vinay Kumar, O.M. Ntwaeaborwa, E. Coetsee, and H.C.Swart, Chemical Engineering Journal ,255,541(2014), DOI: 10.1016/j.cej.2014.06.027

24. M. Zhong, G. Shan, Y. Li, G. Wang, and Y. Liu, Materials Chemistry Physics, 106, 305(2007), DOI: 10.1016/j.matchemphys.2007.06.007

25. L. K. Jangir, Y. Kumari, Anil Kumar, Manoj Kumar and K. Awasthi, Materials Chemistry Frontiers, 1, 1413(2017), DOI: $10.1039 / \mathrm{C} 7 \mathrm{QM} 00058 \mathrm{H}$

26. S. Lakshmi, R. Renganathan, and S.J. Fujita, Journal of Photochemistry and Photobiology A: Chemistry, 88,163(1995), DOI:10.1016/1010-6030(94)04030-6

27. G. Thennarasu and A. Sivasamy, Ecotoxicology and Environmental Safety,134(2), 412(2016), DOI:10.1016/j.ecoenv.2015.10.030

28. N. Daneshvar, D. Salari and A.R. Khataee, Journal of Photochemistry and Photobiology A: Chemistry, 162(2-3),317(2004), DOI:10.1016/S1010-6030(03)00378-2

29. M.A. Behnajady, N. Modirshahla, and R. Hamzavi, Journal of Hazardous Materials, 133(13),226(2006), DOI:10.1016/j.jhazmat.2005.10.022

30. Azita Mohagheghian, Seyydeh-Amene Karimi, Jae-Kyu Yang, and Mehdi Shirzad-Siboni, Journal of Advanced Oxidation Technology, 18,1 (2015), DOI:10.1515/jaots-2015-0108

31. S.H. Sohrabnezhad, M.A. Zanjanchi and M. Razavi, Spectrochimica Acta Part A: Molecular and Biomolecular Spectroscopy, 130, 129(2014), DOI:10.1016/j.saa.2014.02.188

32. H. He, S. Yang, K. Yu, Y. Ju, C. Sun and L. Wang, Journal of Hazardous Materials, 173, 393(2010), DOI:10.1016/j.jhazmat.2009.08.084

33. H. Chen, S. Yang, J. Chang, K. Yu, D. Li, C. Sun, and A. Li, Chemosphere, 89, 185(2012), DOI:10.1016/j.chemosphere.2012.05.050

[RJC-5558/2019] 